Preprint of Touati, K., Tadeo, F., \& Elfil, H. (2017). Osmotic energy recovery from Reverse Osmosis using two-stage Pressure Retarded Osmosis. Energy, 132, 213-224.

Final corrected version in Journal site:

http://www.sciencedirect.com/science/article/pii/S0360544217308071

\title{
Osmotic energy recovery from Reverse Osmosis using two-stage Pressure Retarded Osmosis
}

\author{
Khaled Touati ${ }^{\mathrm{a}, \mathrm{b}}$ \\ ${ }^{a}$ Laboratory of Natural Water Treatment- Water Researches and Technologies Center, \\ Techno-park Borj Cedria, BP 273, 8020, Soliman, Tunisia. Tel: + 21679325122 / \\ 79325199; Fax: + 21679325802. \\ ${ }^{b}$ Department of Systems Engineering and Automatic Control, University of \\ Valladolid, 47011, Valladolid, Spain. Tel: +34 983423162; Fax: +34 \\ 98342316.kha.touati@gmail.com.
}

\section{Jacobo Salamanca ${ }^{\mathrm{b}}$}

${ }^{b}$ Department of Systems Engineering and Automatic Control, University of Valladolid, 47011, Valladolid, Spain. Tel: +34 983423162; Fax: +34 98342316.

\author{
Fernando Tadeo ${ }^{\mathrm{b}, *}$ \\ ${ }^{b}$ Department of Systems Engineering and Automatic Control, University of \\ Valladolid, 47011, Valladolid, Spain. Tel: +34 983423162; Fax: +34 98342316. \\ *Corresponding author:fernando@autom.uva.es.
}

\section{Hamza Elfil $^{\mathrm{a}}$}

${ }^{a}$ Laboratory of Natural Water Treatment- Water Researches and Technologies Center, Techno-park BorjCedria, BP 273, 8020, Soliman, Tunisia. Tel: + 21679325122 / 79325199; Fax: + 216 79325802. elfilhamza@gmail.com. 


\section{$\underline{\text { Abstract: }}$}

The integration of Pressure Retarded Osmosis (PRO) with Seawater Reverse Osmosis (SWRO) is studied here, concentrating on the effect on the overall energy consumption and on the effluents. For this, two alternative designs are evaluated: a previously studied one-stage PRO (SWRO-1PRO) and a newly proposed two-stage PRO (SWRO-2PRO). The analysis results obtained from extrapolation of laboratory data using models show better performance for SWRO-2PRO (without using external impaired low-salinity water flows). The improvement of performance thanks to PRO increases with the increase of the feed concentration and flow.

Keywords: Pressure Retarded Osmosis; Seawater Reverse Osmosis; Energy recovery; Membrane; Dilution Factor.

\section{Introduction}

The Earth is a watery place [1]. More than 71 percent of the Earth's surface is watercovered; however 97 percent of this water is saline with only 3\% freshwater [2]. Meanwhile, the population is in a constant need of potable water for several vital uses such as agricultural, industrial and other. Consequently, water scarcity is becoming an increasingly significant problem [3]. A statistical study showed that around $20 \%$ of the world's population lives with a lack of potable water, while $80 \%$ may face water scarcity during the next decade [4]. One of the proposed solutions to face this worldwide problem and to overcome the fresh water scarcity is saline water desalination. Several desalination techniques were then commercialized, such as Multi-Effect Distillation (MED), Multistage Flash distillation (MSF), Electrodialysis (ED), and Reverse Osmosis (RO) [5]. The $\mathrm{RO}$ process is one of the most popular and an efficient method that leads the desalination industry with about $60 \%$ of produced water [6,7]. Compared to available desalination processes, RO is considered the most energy-efficient technology. However, it is still considered that RO energy consumption should be reduced [8]. Specific Energy Consumption (SEC) reduction has monopolized the focus of technological innovation and research in this sector. The energy costs in seawater reverse osmosis (SWRO) plants may reach $50 \%$ of the final costs of the produced water. Consequently, reducing the 
energy consumption has been intensively investigated to decrease the energy cost of RO systems. The investigations were focusing on manufacturing high performance membranes [9], incorporating higher efficiency pumps, integrating energy recovery technologies [10] and renewable energies [11]. Salinity gradient energy, which is released when two solutions with different concentrations are mixed, is considered to be a promising source of sustainable energy [12]. Pressure Retarded Osmosis (PRO) has been one of the most widely investigated processes [13]. In a PRO process, a semi-permeable membrane is used to separate a low concentration stream (feed solution) and a high concentration stream (draw solution) to. If a hydraulic pressure lower than the osmotic pressure difference between the feed and draw solutions is applied on the draw solution side, the water permeates across the membrane from the feed solution to the draw solution. Then, the volume of the draw solution is expanded. The diluted draw solution is partially depressurized through a hydro-turbine to generate electricity [14]. SWRO brine could be used as a PRO draw solution to reduce the energy consumption of the desalination process $[15,16]$. In fact, this brine is characterized by i) relatively high concentration, ii) pre-treated by the RO pre-treatment system, iii) controlled by the recovery demand. These characteristics may reduce the energy consumption by avoiding the pretreatment of PRO draw solution compared to a stand-alone PRO unit $[17,24]$. Moreover, The SWRO brine is still an environmental problem that should be solved [18]. It is projected that 36 million $\mathrm{m}^{3} /$ day of desalinated water will be produced by SWRO by 2016 [19]. Therefore, similar amount of brine will be discharged in the sea in the same year. Integrating PRO with SWRO can be a solution for brine dilution before being released in the sea. As a consequence of these attractive advantages, the integration of PRO into SWRO has attracted the attention of many researchers and several studies are currently involved in investigating the feasibility of SWRO-PRO systems [20-25]. However, to the best of our knowledge, no works were published to study the feasibility of integrating two PRO stages with two-stage SWRO for water and energy production. In previous works, it was shown that increasing the number of SWRO stages reduces the energy consumption of the process [26]. In the current work, for the first time, a theoretical study discussing the energy efficiency of two-stage SWRO connected to twostage PRO is developed in the current work. For this, a model of the process was developed, and the results were compared to a similar SWRO-PRO design containing only a one-stage PRO sub-system. In addition, a comparison between the performance of pressure exchangers and PRO in both ideal and real cases (taking into account the 
[Escriba aquí]

latest developments of PRO membranes and their detrimental effects) was raised to identify their efficiency in light of the latest technological development.

\section{Material and method}

\subsection{SWRO plant}

As a case study, a SWRO plant for producing water for an electrolyzation process is used (see Fig.1), which was developed by the company SETA, S-L as a part of the H2OCEAN project [27]. The desalination unit is based on two independent lines, divided into two stages. Pre-treatment composed of three processes: chlorination, ultra-filtration, and backwash. The first pass of the SWRO unit begins with a chemical treatment to remove the residual chlorine; then, bisulphate and antifouling are added.A5 microns micro filter is installed just before the High Pressure Pump (HP).A Pressure exchanger recovers hydraulic energy from the brine. The recovery factor is selected to be $45 \%$ for the First Pass and $70 \%$ for the Second Pass. The brine of the second pass goes to an energy recovery system before being reused in the proposed osmotic energy recovery system.

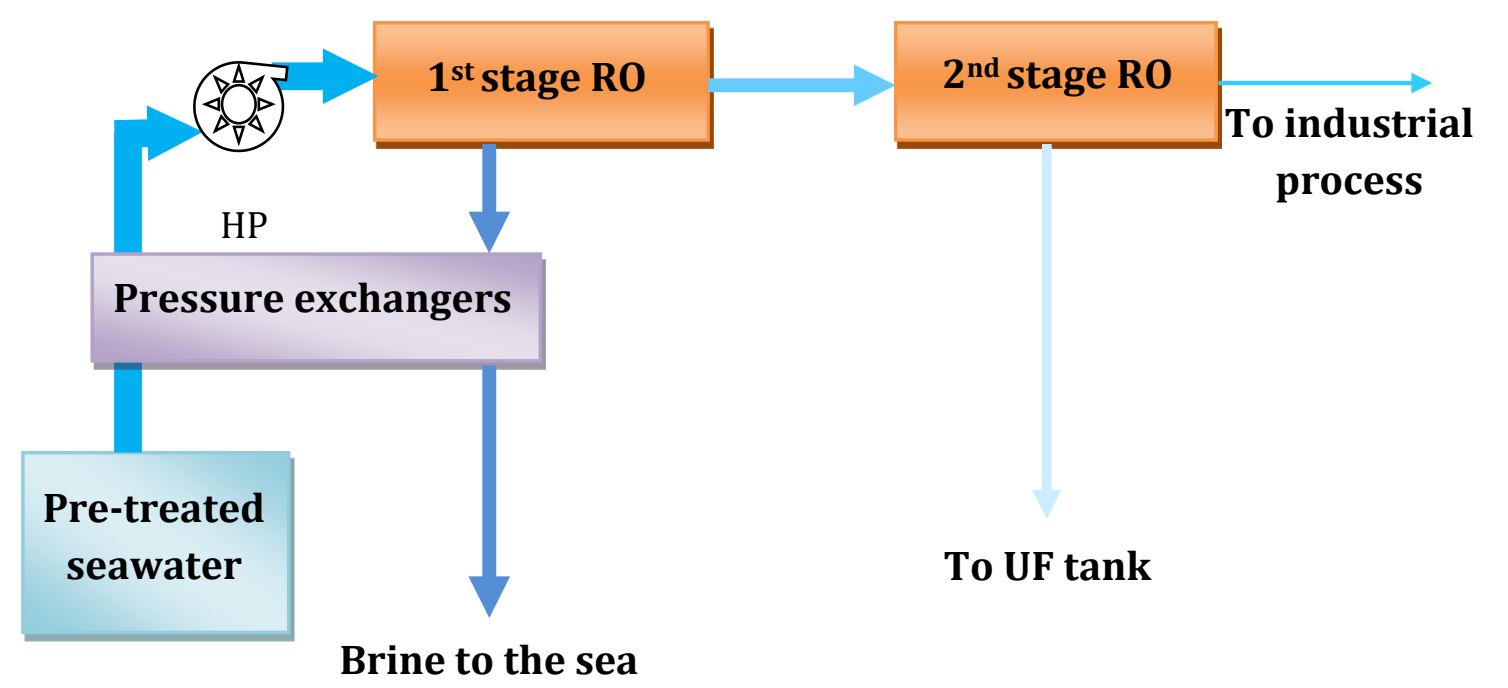

Fig.1: Two-stage reverse osmosis desalination unit. Darker colors correspond to more concentrated solutions and arrow thickness represents the approximate flow rate.

\subsection{SWRO-PRO designs}

a. “2RO-1PRO”integration design

A simplified presentation of the first SWRO-PRO design is presented in Fig.2: the seawater flow $\left(\mathrm{Q}_{\mathrm{sw}}\right)$ is first pre-pressurized using the pressure exchanger $\mathrm{PX}$ prior to 
entering the desalination process. Exiting the first stage SWRO sub-system $\left(\mathrm{RO}_{1}\right)$ are two streams: fresh water permeate stream $\left(Q_{p}\right)$ and a concentrated brine stream $\left(Q_{R}^{1}\right) \cdot Q_{R}^{1}$ is then depressurized to reach an adequate pressure condition for the PRO process [28]. The permeate of the $\mathrm{RO}_{1}$ feeds the second stage $\mathrm{RO}$ sub-system $\left(\mathrm{RO}_{2}\right)$. To recover the brine energy, an isobaric or turbocharged device could be used; alternatively, a turbine could be used to convert it into electrical energy. Following this depressurization, the brine stream enters the PRO sub-system as a high salinity (draw) solution $\left(Q_{R}^{1}=Q_{D}\right)$. The feed solution for the PRO sub-system is the retentate of the second stage $\left(Q_{F}=Q_{R}^{2}\right)$. Through osmosis, the pressurized draw solution extracts water from the impaired water source under isobaric conditions, resulting in a diluted draw solution (QDR). Through osmosis, the pressurized draw solution extracts water from the impaired water source under isobaric conditions, resulting in a diluted draw solution ( $\left.Q_{D R}\right)$. The energy stored in the diluted draw solution is then exchanged with the seawater $\mathrm{RO}_{1}$ feed prior to discharge in order to recover its potential energy and increase the energy savings of the SWRO-PRO system. The PRO feed solution bleed $Q_{F R}$ is rejected to the sea. $Q_{P}^{2}$ is the permeate flow of the second RO stage.

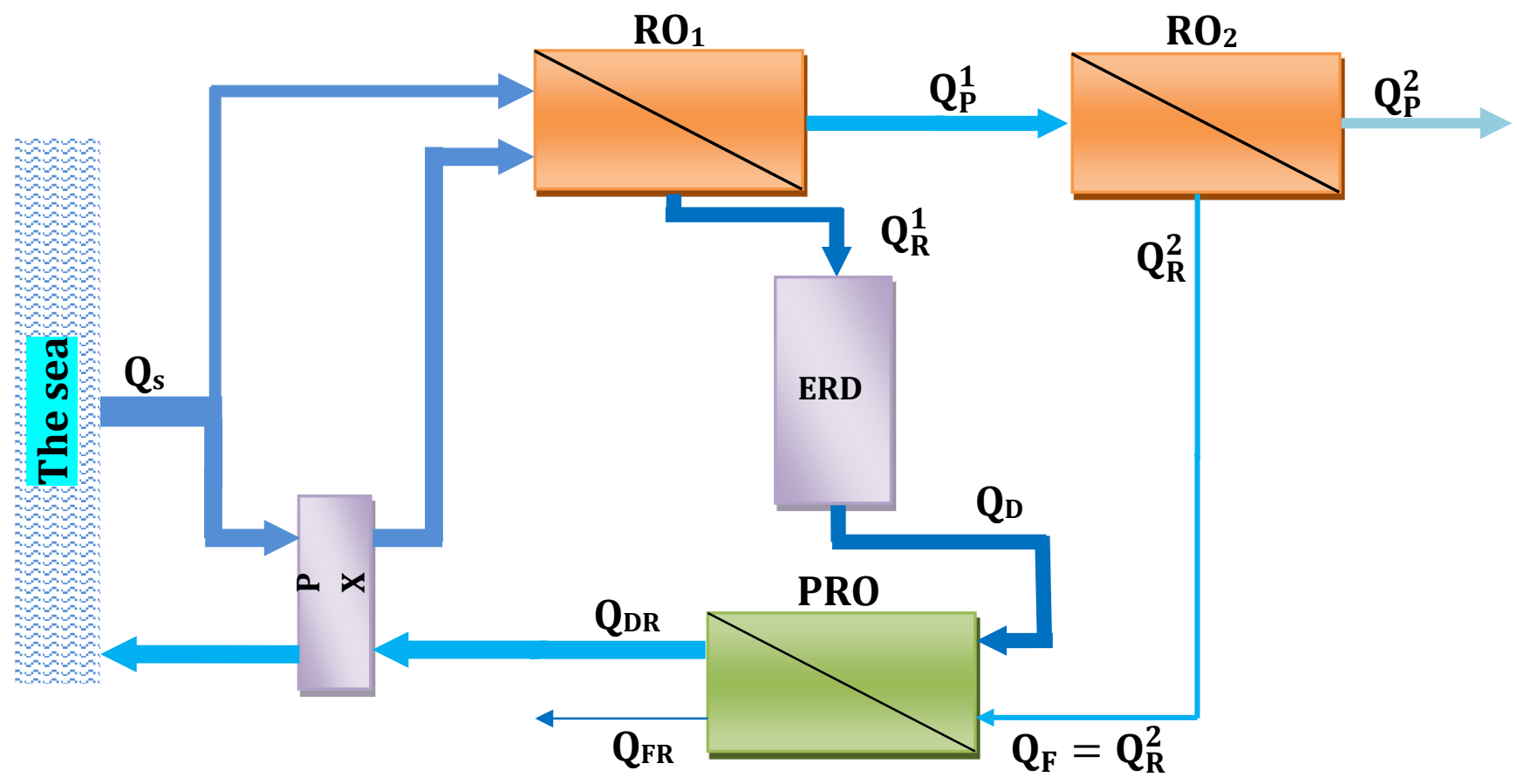

Fig. 2: First integration design “2RO-1PRO”. Darker colors correspond to more concentrated solutions and arrow thickness represents the approximate flow rate.

b. “2RO-2PRO”integration design 
The osmotic pressure difference between the feed and draw solutions, $\Delta \pi$, is one of the most important parameters in the PRO process [29]. In fact, it is the driving force of the water from the draw side to the feed side. In addition, as shown in previous works $[30,34,35]$, the initial feed flow rate fraction, $\phi$, defined as the ratio of the initial mass flow rate of the feed solution to the sum of the initial mass flow rates of both feed and draw solutions, is also a key parameter when operating at constant applied pressure. Therefore, to optimize the energy production, these two parameters were considered in the second design, where two PRO sub-systems are connected to the process. The draw solution of the first PRO sub-system $\left(\mathrm{PRO}_{1}\right)$ is the retentate of the first $\mathrm{RO}$ stage and the feed solution is pre-treated seawater, called here $\mathrm{Q}_{\mathrm{ad}}$. The amount of $\mathrm{Q}_{\mathrm{ad}}$ is chosen to be equal to $\mathrm{Q}_{\mathrm{R}}^{1}$.For this, a controllable valve $(\mathrm{V})$ is placed to provide the desired amount of $\mathrm{Q}_{\mathrm{ad}}$. The retentate of the second $\mathrm{RO}$ stage feeds the second PRO sub-system $\left(\mathrm{PRO}_{2}\right)$. The sweater bleed from $\mathrm{PRO}_{1}, \mathrm{Q}_{\mathrm{FR}}$, represents the draw solution of the second PRO subsystem. Qfr is firstly pressurized using a high pressure pump (HP). This pressure is considered to be half the osmotic pressure difference between the draw and feed solutions of $\mathrm{PRO}_{2}$. The pressurized flow $\mathrm{Q}_{\mathrm{t}}$ is then conducted to a turbine for electricity generation. It should be pointed out here that the energy recovery device (ERD) is theoretically functionless when $\mathrm{Y}_{1} \leq 50 \%$. Above $50 \%$, part of the hydraulic pressure of $\mathrm{RO}_{1}$ retentate can be recovered to pressurize the $\mathrm{PRO}_{1}$ seawater bleed.

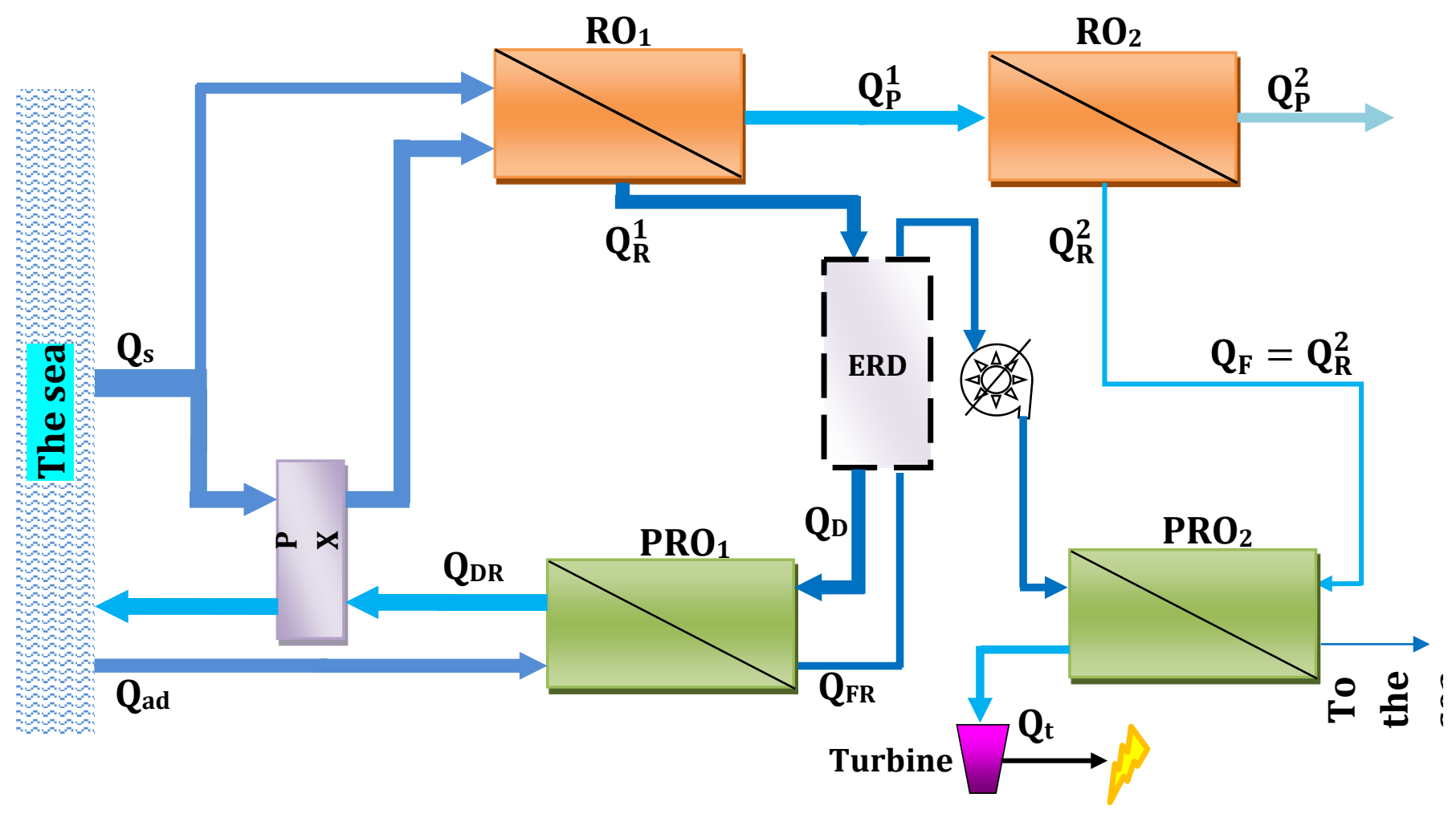


Fig. 3: Second integration design “2RO-2PRO”.Darker colors correspond to more concentrated solutions and arrow thickness represents the approximate flow rate.

\section{3. $\quad$ Modeling}

\subsubsection{Thermodynamics}

When we mix two solutions with different compositions and concentrations, an energy known as the Gibbs free energy of mixing is released. This energy release is achievable only under reversible process. In a reversible PRO process, the energy produced is equal to the Gibbs free energy of mixing [30]. The molar Gibbs free energy of mixing, $\Delta G_{m}$, is the energy per mole of mixed solution produced in a isothermal and isobaric mixing [30] defined as:

$\Delta G_{m}=\sum_{i} x_{i, M} \ln \left(\gamma_{i, M} x_{i, M}\right)-\frac{n_{F}}{n_{M}} \sum_{i} x_{i, F} \ln \left(\gamma_{i, F} x_{i, F}\right)-\frac{n_{D}}{n_{M}} \sum_{i} x_{i, D} \ln \left(\gamma_{i, D} x_{i, D}\right)$

Where $\mathrm{n}_{\mathrm{M}}, \mathrm{n}_{\mathrm{F}}$, and $\mathrm{n}_{\mathrm{D}}$ are the total amounts (in moles) of mobile species in the mixed, feed, and draw solutions, respectively; $x_{\mathrm{i}, \mathrm{M}}, x_{\mathrm{i}, \mathrm{F}}$, and $x_{\mathrm{i}, \mathrm{D}}$ are the mole fractions of species "i" in the mixed, feed, and draw solutions, respectively; and $\gamma_{\mathrm{i}, \mathrm{M}}, \gamma_{\mathrm{i}, \mathrm{F}}$, and $\gamma_{\mathrm{i}, \mathrm{D}}$ are the activity coefficients of species "i” in the corresponding solutions. For dilute solutions, the activity coefficients are approximated as unity. Eq (1) can be simplified to be the specific Gibbs free energy of mixing per volume of total mixed solution, by assuming a negligible contribution of the solute to the volume of the solution. Therefore, $\Delta G_{V}$ is expressed as: as a function of the molar concentrations of the feed, draw, and mixed solutions, as well as the feed volume fraction, $\phi$ :

$\frac{\Delta \mathrm{G}_{\mathrm{V}_{\mathrm{M}}}}{\beta R T}=\mathrm{C}_{\mathrm{M}} \ln \left(\mathrm{C}_{\mathrm{M}}\right)-\phi \mathrm{C}_{\mathrm{F}} \ln \left(\mathrm{C}_{\mathrm{F}}\right)-(1-\phi) \mathrm{C}_{\mathrm{D}} \ln \mathrm{C}_{\mathrm{D}}$

where $C_{F}, C_{D}$, and $C_{M}$ are the molar concentrations of the feed, draw, and mixed solutions, respectively. $\phi$ is the flow ratio defined as $\mathrm{n}_{\mathrm{F}} / \mathrm{n}_{\mathrm{M}}=\phi, \mathrm{n}_{\mathrm{D}} / \mathrm{n}_{\mathrm{M}}=1-\phi$ and $\beta$ is the van't Hoff factor for strong electrolytes (e.g., $\beta=2$ for $\mathrm{NaCl}$ ). Eq. (2) cannot be directly used due to the fact that $\mathrm{C}_{\mathrm{M}}$ is unknown. A previous work [30] developed an expression of the specific ideal work, $W_{\mathrm{Q}_{\mathrm{F}}^{0}}^{\text {ideal }}$, defined as energy per unit volume of the initial feed solution when $\Delta P=\Delta \pi$ throughout reversible thermodynamic: 
[Escriba aquí]

$\mathrm{W}_{\mathrm{Q}_{\mathrm{F}}^{0}}^{\text {ideal }}=\frac{\Delta \mathrm{G}_{\text {mix,ideal }}}{\beta R T}=\mathrm{C}_{\mathrm{FIN}} \ln \left(\mathrm{C}_{\mathrm{FIN}}\right)-\phi \mathrm{C}_{\mathrm{F}}^{0} \ln \left(\mathrm{C}_{\mathrm{F}}^{0}\right)-(1-\phi) \mathrm{C}_{\mathrm{D}}^{0} \ln \mathrm{C}_{\mathrm{D}}^{0}$

where, $C_{F}^{0}$ and $C_{D}^{0}$ are the initial feed and draw solution concentrations, respectively. $\mathrm{C}_{\mathrm{FIN}}$ is the concentration of the mixed solution when no longer water permeation, in other words, when the concentrations of the draw and feed solutions are equals and the net osmotic driving force vanishes (i.e., $\Delta \pi=0$ ). The concentration $\mathrm{C}_{\mathrm{FIN}}$ is defined as [30]:

$C_{F I N}=(1-\phi) C_{D}^{0}+\phi C_{F}^{0}$

The amount of permeate, $\Delta Q_{F I N}$, that ultimately passes into the draw solution can be calculated by is expressed as:

$\Delta Q_{F I N}=Q_{F}^{0}\left(1-\frac{C_{F}^{0}}{C_{F I N}}\right)$

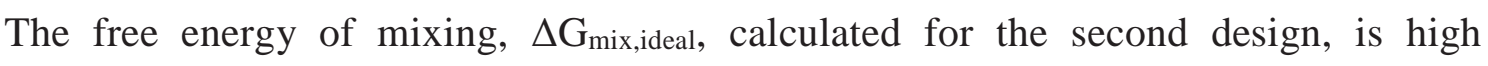
compared to the first design. At 50\% recovery, the theoretical maximum extractable energy is $0.32 \mathrm{kWh} / \mathrm{m}^{3}$ compared to $0.2 \mathrm{kWh} / \mathrm{m}^{3}$ for the first stage. Theoretical analysis shows a better performance for the second design. This study is now compared with realistic res0.0ults developed in the up-coming section. 

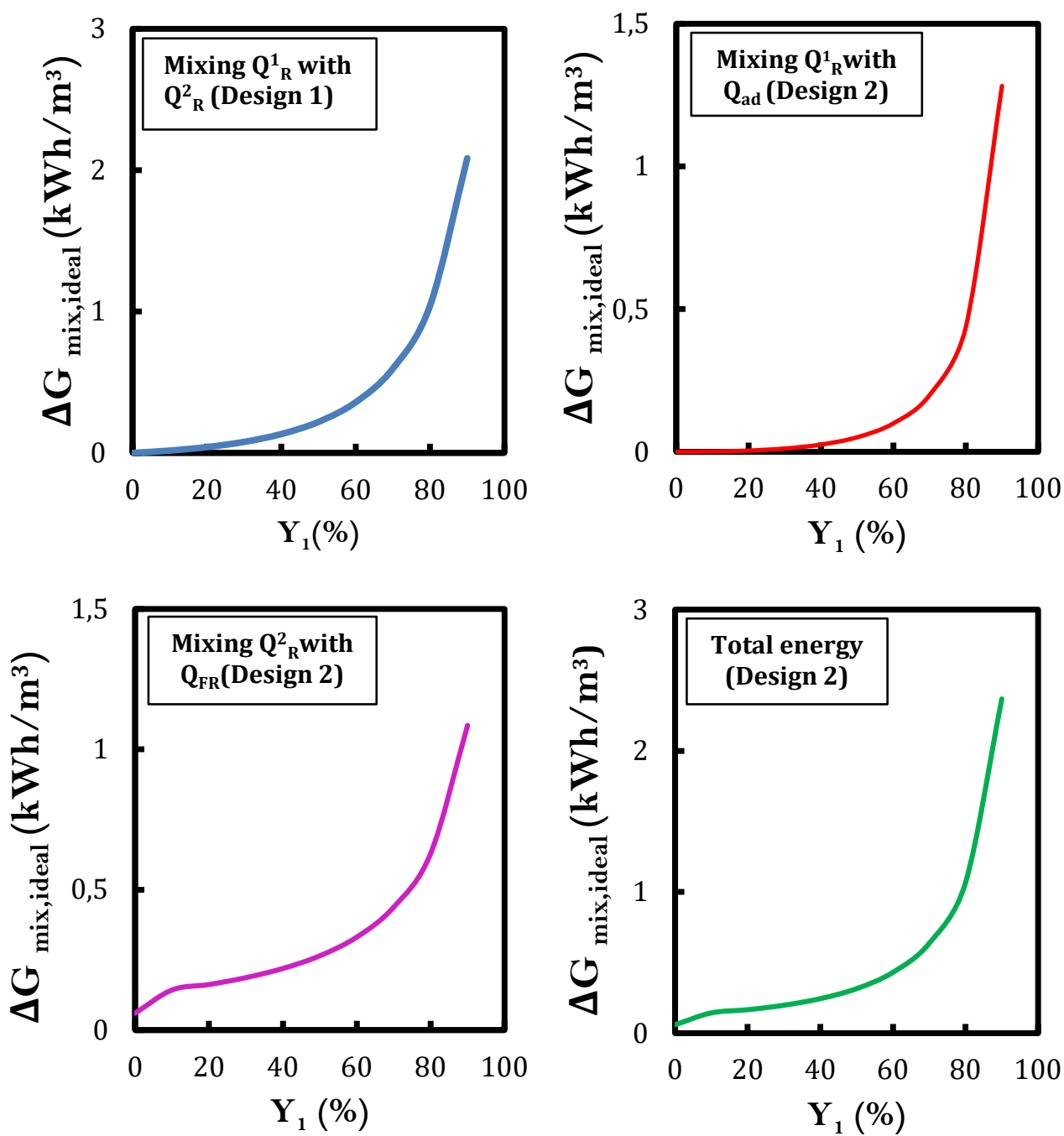

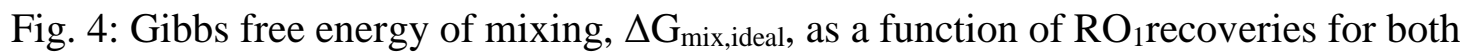
designs described in section 2.2. The change in free energy of mixing is expressed as the energy released per unit volume of the feed solution. The flows $Q_{R}^{1}$ and $Q_{R}^{2}$ were calculated using recoveries, $\mathrm{Y}_{1}$ and $\mathrm{Y}_{2}$.

\subsubsection{Minimum specific energy of SWRO plant.}

Specific energy consumption is an important parameter in RO. It is defined as pump energy consumption per unit amount of produced permeate water. The minimum specific energy (SE) represents the energy needed to produce a unit volume of permeate, when the applied hydraulic pressure is equal to the brine osmotic pressure at exit of the membrane module. Consequently, SE can be expressed using the initial osmotic pressure, $\pi_{\text {feed, }}$ and the recovery ratio, Y. At the theoretical limit of constant-pressure operation, the RO system operates with an applied hydraulic pressure that is equal to the final osmotic pressure of the brine exiting the RO module. Therefore, the minimum specific

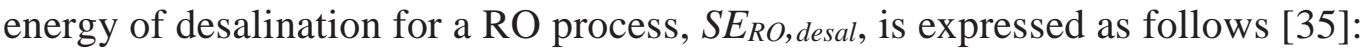


[Escriba aquí]

$S E_{R O, \text { desal }}=\frac{\pi_{f e e d}}{1-Y}$

where $\pi_{\text {feed }}$ is the osmotic pressure of the RO feed solution and $Y$ is the recovery ratio of the RO module. In our case, two RO stages are considered where the permeate of the first stage feeds the second stage. The specific energy consumption per volume of freshwater ( $\mathrm{SEC}_{\mathrm{RO}}$ ) for each stage is:

$S E C_{R O_{1}}=\frac{\pi_{S w}}{1-Y_{1}}$

$S E C_{R O_{2}}=\frac{\pi_{p}^{\prime}}{1-Y_{2}}$

where the subscripts 1 and 2 refer to the first and second RO stage. Consequently, the total theoretical energy consumption of the two-stage RO system, $S E C_{R O_{1}-R O_{2}}$, is the sum of the energy consumption of each stage:

$S E C_{R O_{1}-R O_{2}}=\pi_{S W}\left(\frac{1}{1-Y_{1}}+\frac{Y_{1}}{1-Y_{2}}\right)$

Fig. 1 describes the theoretical energy consumption of the two-stage SWRO as a function of $\mathrm{Y}_{1}$ according to Eq. (9). In this case, since the majority of the energy is consumed by the first stage, the recovery of the second stage is maintained equal to $70 \%$ throughout the study .As can be seen in Fig. 5, the minimum energy needed to produce a volume unit of fresh water in the second stage is $0.83 \mathrm{kWh} / \mathrm{m}^{3}$. This value is in coherence with the thermodynamic results developed in the previous section. This lower limit corresponds to a rate of production that is nearly zero. It can also be seen that, when the recovery rate increases, the specific energy consumption increases too. For the one-stage SWRO system, it has been shown in the literature that the optimal recovery rate for a SWRO unit is around $40 \%$ to $50 \%$ [24]. For these recovery rates, the $\mathrm{SEC}_{\mathrm{RO} \text {,theo }}$ in our case would be between 1.24 to $1.49 \mathrm{kWh} / \mathrm{m}^{3}$. 
[Escriba aquí]

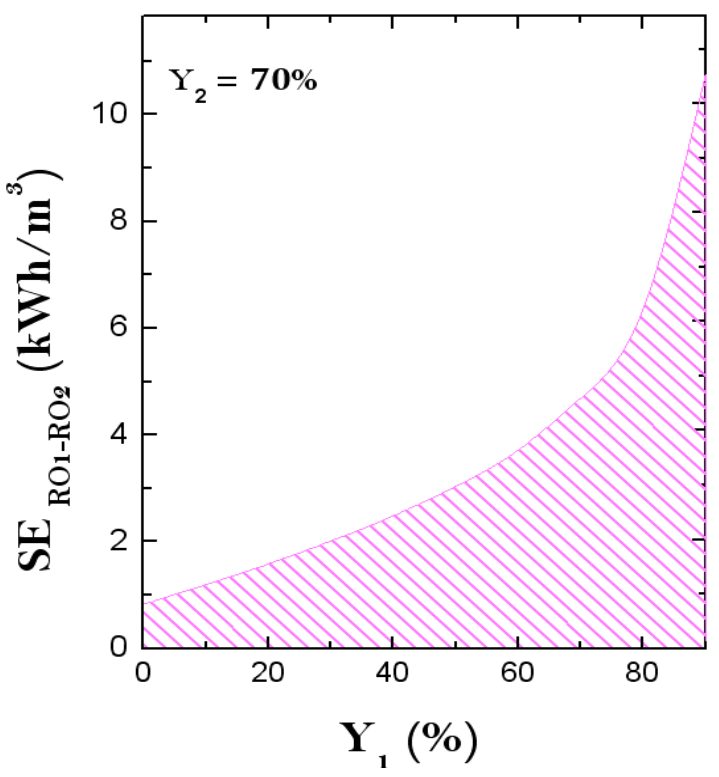

Fig.5: Specific

$Y_{1}(\%)$

energy consumption

of the proposed two-stage seawater desalination, $\mathrm{SEC}_{\mathrm{RO} 1-\mathrm{RO} 2}$, as a function of water recovery of the first stage, $Y_{1}$.

\subsubsection{Specific energy production of the PRO process}

In PRO Lab-scale, the water flux across the membrane, $J_{w}$, is a key parameter to evaluate the performance of the PRO process. As a hydraulic pressure $\Delta P$ is applied here, a power density (PD), defined as the product of the trans-membrane water flux, is generated. This power density represents the power generated per membrane area, expressed as follows:

$P D=J_{w} \Delta P$

For a full-scale system, PD cannot be considered constant along the module, due to several causes such as the variation of the pressure and the solution concentrations along the module. In this case, the average power density $\overline{P D}$ is considered:

$\overline{P D}=\frac{\Delta P \Delta Q}{A_{m}}$

where $\Delta Q$ is the trans-membrane water flow rate for the entire module and $A_{m}$ is the total membrane area. To guarantee maximum energy production using PRO, the operating conditions should be well controlled. Besides the physico-chemical parameters of the treated solutions (concentrations, temperatures, nature of ions, etc...), the apparent operation conditions, in particular the applied pressure $\Delta \mathrm{P}$ and the feed flow fraction $\phi$, have been revealed as an important parameters in full-scale PRO process. In fact, $\Delta \mathrm{P}$ is 
directly proportional to the energy produced, which means that its value should be well chosen [30]. In addition, previous work has found that the optimal feed flow rate fraction, $\phi$, is one-half, in other words, the flow rates of feed and draw solution are equals. During ideal PRO processing, the optimal applied hydraulic pressure at this feed flow rate fraction in is equal to half the initial osmotic pressure difference $\Delta P=\Delta \pi / 2$ [34]. Regardless of the flow configuration and operation regime, SEpro, can be expressed as [35]:

$S E=\frac{\Delta P \Delta Q}{Q_{F}+Q_{D}}$

Inversely to the RO system, PRO dilutes the draw solution by means of the permeate flow across the membrane. Respecting the analogy between RO and PRO, the dilution factor of the draw solution in the PRO system, DF, is defined as follows:

$D F=\frac{\Delta Q}{Q_{D}}$

The DF indicates the fraction of PRO feed solution in the diluted brine after PRO. A DF approaching $0 \%$ indicates the draw solution is not diluted, while a DF approaching $100 \%$ indicates the draw solution is diluted by all the feed solution volume (e.g., $\Delta \mathrm{Q}=\mathrm{Q}_{\mathrm{D}}$ ). As mentioned in section 2.3, $\phi$, which is the initial feed flow rate fraction and is defined as the ratio of the initial mass flow rate of the feed solution to the sum of the initial mass flow rates of both feed and draw solutions, represented as:

$\phi=\frac{Q_{F}}{Q_{F}+Q_{D}}$

The PRO entering flow ratio, $r$, is defined as:

$r=\frac{Q_{F}}{Q_{D}}$

Substituting Eq.(13), Eq.(14) and Eq.(15) in Eq.(12) gives the specific energy production of the first PRO design: 
[Escriba aquí]

$S E_{P R O}^{1}=\frac{\phi D F}{2 r}\left(C_{R 1}-C_{R 2}\right) \beta R T$

a. 2RO-1PRO energy model

In the first SWRO-PRO, the brines of the first and second stages feed the PRO system. Thus, $\mathrm{Q}_{\mathrm{D}}$ and $\mathrm{Q}_{\mathrm{F}}$ depend on the recoveries of the RO modules. Consequently, the parameters $\phi$ and $r$ are also functions of $\mathrm{Y}_{1}$ and $\mathrm{Y}_{2}$. Then, inserting the recoveries $\mathrm{Y}_{1}$ and $\mathrm{Y}_{2}$ in Eq.(17) and Eq.(18) gives:

$\phi=Y_{1} \frac{1-Y_{2}}{1-Y_{1} Y_{2}}$

$r=Y_{1} \frac{1-Y_{2}}{1-Y_{1}}$

$\frac{\phi}{r}=1-\phi$

Finally, the expression of $S E_{P R O}^{1}$ is as follows:

$S E_{P R O}^{1}=\operatorname{DF}(1-\phi)\left(C_{R}^{1}-C_{R}^{2}\right) \frac{\beta R T}{2}$

Eq.(20) cannot be directly used. In this case, it is obvious that the entering flows of the PRO feed and draw solutions are not equal. In fact, when the recovery of the first stage is lower than $77 \%$, the draw solution flow is much bigger than the feed solution flow. Consequently, the maximum dilution should be determined, firstly, to calculate the specific energy SEPRo. Regardless of the membrane performance, the boundaries of the permeate flow across the PRO membrane are $0 \leq \Delta Q \leq Q_{F}$. In other words, the maximum dilution that can be reached with a perfect semi-permeable membrane with no detrimental effects is reached when $\Delta Q=Q_{F}$. The dilution factor, DF, can be described as follows by rearranging Eq.(13):

$D F=x r$ 
wherex is an empirical parameter that reflects the performance of the PRO membrane, and $r$ is the feed flow ratio. The parameter $x=\frac{\Delta Q}{Q_{F}}$ is determined theoretically by rearrangement of Eq.(5) as follows:

$x=\frac{\Delta Q}{Q_{F}}=1-\frac{\mathrm{C}_{\mathrm{R}}^{2}}{\mathrm{C}_{\mathrm{FIN}}}$

where $\mathrm{C}_{\text {FIN }}$ is the final concentration of the mixed feed and draw solution, calculated using Eq. (4). We admit that:

$0 \leq x \leq 1\left\{\begin{array}{c}\mathrm{x} \leq 0.3 \rightarrow \text { low mixing rate } \\ 0.4 \leq \mathrm{x} \leq 0.6 \rightarrow \text { medium mixing rate } \\ 0.6<x \rightarrow \text { high mixing rate }\end{array}\right.$

Based on the variation of $\mathrm{RO}_{1}$ recovery, the dilution factor can be calculated. Fig.6 shows the influence of the PRO entering flow ratio, $r$, and the membrane performance, $x$, on the dilution of the draw solution. It can be seen that when the recovery increases, the dilution factor increases too, because of the increase of $Q_{R}^{2}$ and the decrease of $Q_{R}^{1}$. Similarly, the increase in the membrane performance increases the dilution factor. The maximum dilution that can be achieved when $\mathrm{Y}_{1}=50 \%$ is almost $30 \%$, using high membrane performance $(x=1)$; while full dilution is achievable using high membrane performance when $\mathrm{Y}_{1}=77 \%$. Unfortunately, high recoveries are not advisable in the RO process due to several limitations [36,37]. Moreover, with a realistic membrane and hydrodynamics, several detrimental effects occur (concentration polarization, salt diffusion, fouling...) [36,38]. Consequently, full dilution in realistic conditions is not achievable even at high recovery rates. After being determined, the dilution factors are used in Eq.(23) to calculate the specific energy production SEPRo. Fig.7 (left side) shows the variation of SEPRo with the dilution for different $\mathrm{RO}_{1}$ recoveries. The maximum dilution that can be achieved for chosen recoveries is around $40 \%$, when $\mathrm{Y}_{1}=60 \%$. In this case, the maximum energy produced is almost $0.28 \mathrm{kWh} / \mathrm{m}^{3}$. At low recoveries, the energy recovered is not significant, due to the low dilution of the draw solution (i.e., $\mathrm{SEPRO}=0.065 \mathrm{kWh} / \mathrm{m}^{3}$ when $\mathrm{Y}_{1}=30 \%$ ). The energy was almost quadrupled when the recovery increased from $30 \%$ to $60 \%$. Meanwhile, this increase corresponds to tripled dilution values even when the energy is directly proportional to the dilution. This behavior is due to the contribution of 
$\phi$, which tends towards its optimized value $(\phi=0.5)$ when the recovery increases, as can be seen in Fig.7 (right).
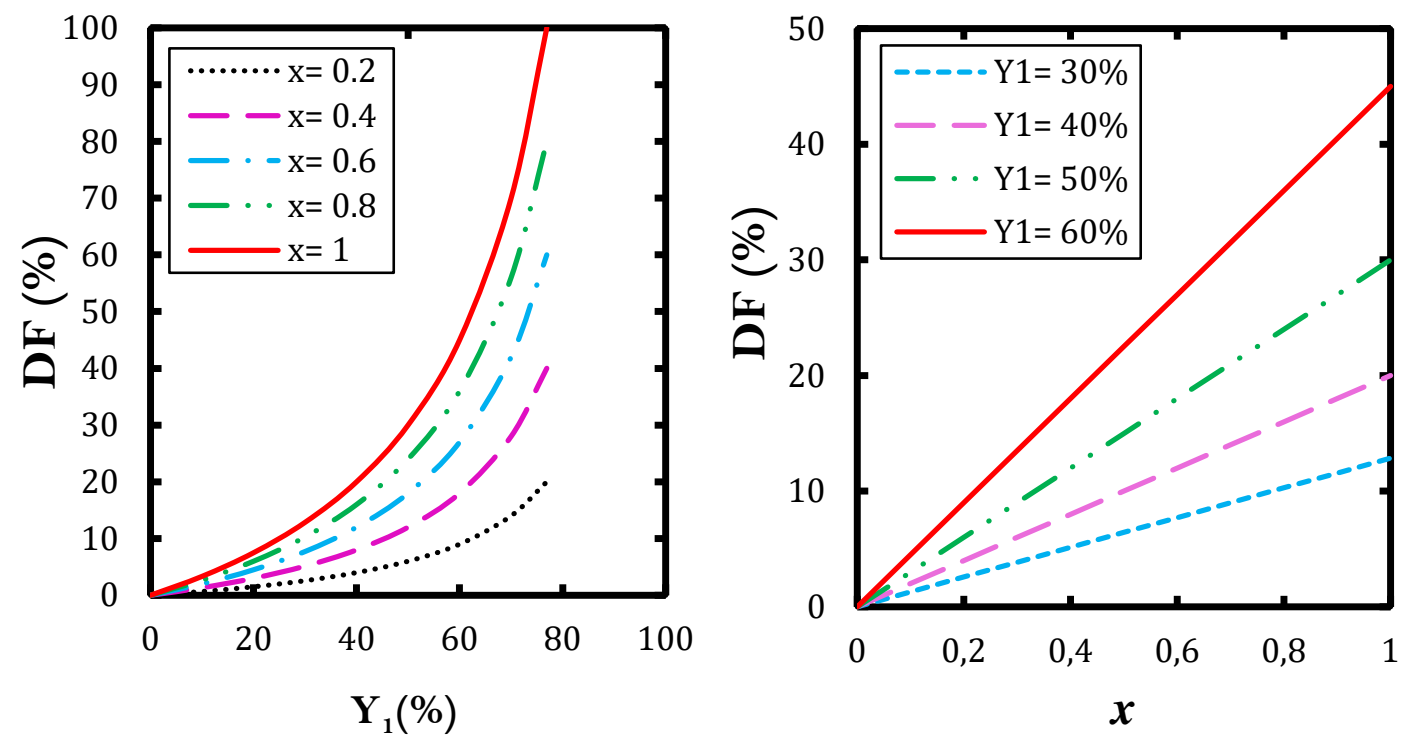

Fig.6: Variation of the dilution factor as a function of the recovery ratio $\mathrm{Y}_{1}$ for different membrane performances.
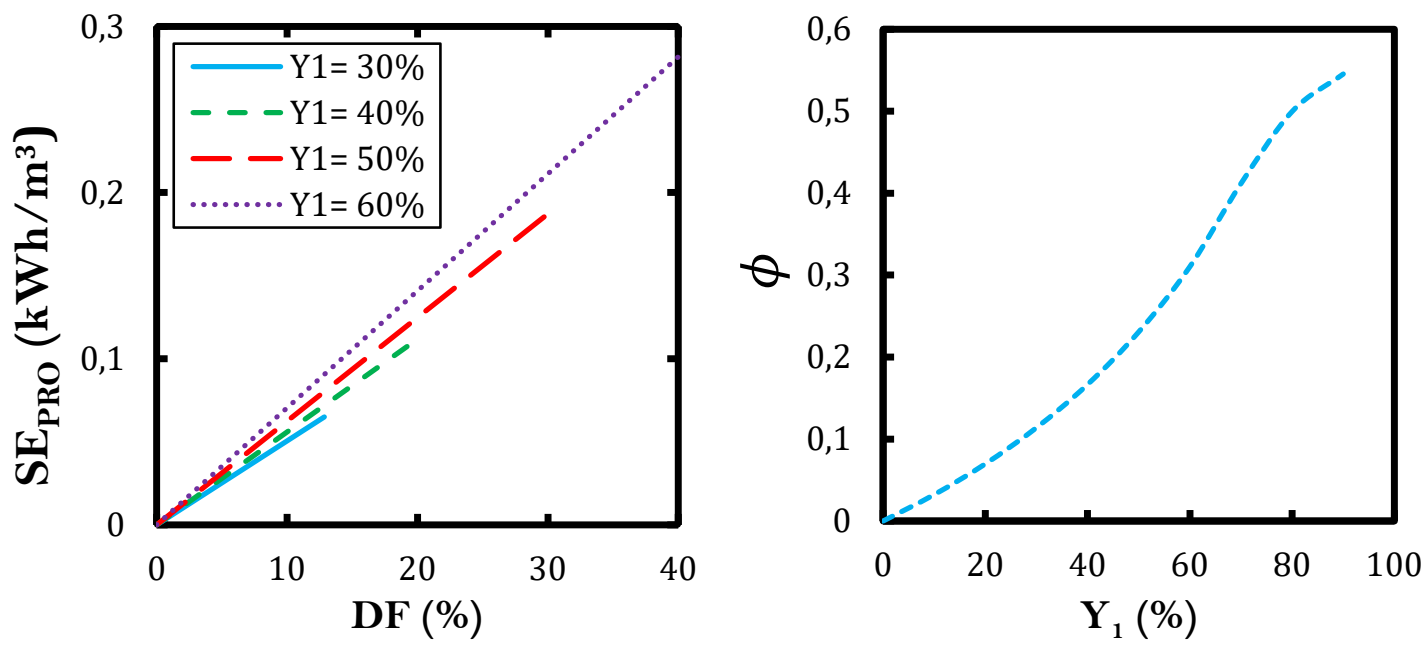

Fig.7: Specific energy production SEpro and the initial mass flow rate of both feed and draw solutions, $\phi$, for "2RO-1PRO" design as a function of dilution for different $\mathrm{RO}_{1}$ recoveries.

\section{b. 2RO-2PRO energy model}

During the second SWRO-PRO processing, two PRO sub-systems were integrated in the SWRO plant to maximize energy recovery. To optimize the performance of $\mathrm{PRO}_{1}$, the entering flows of the first PRO sub-system $\left(Q_{F}\right.$ and $\left.Q_{D}\right)$ were maintained equal thanks to 
the added pre-treated seawater flow $Q_{a d}=Q_{R}^{1}$. Respecting the condition $Q_{D}=Q_{F}$, the expression of the first stage PRO energy production, $S E_{P R O}^{2.1}$, becomes:

$S E_{P R O}^{2.1}=\frac{\beta R T}{4}\left(C_{R}^{1}-C_{S W}\right) D F_{P R O_{1}}$

where $\mathrm{DF}_{\mathrm{PRO}_{1}}$ is the dilution factor of the second PRO stage. Fig.8 shows the variation of the energy recovered respecting the performance of the PRO membrane for different $\mathrm{RO}_{1}$ recoveries. As expected, high recoveries induce high energy production due to the increase in the osmotic pressure of the PRO draw solution. In addition, a high performance of the membrane leads to an increase of energy by increasing the dilution. Also, the optimized feed flow ratio $\phi$ guarantees the enhancement of energy recovery, as seen previously in section 2.3.3. In this design case, the two PRO sub-systems are linked, where the feed bleed solution of $\mathrm{PRO}_{1}$ is the draw solution of $\mathrm{PRO}_{2}$. Consequently, the performance of the $\mathrm{PRO}_{1}$ membrane governs that of $\mathrm{PRO}_{2}$. The draw solution flow of $\mathrm{PRO}_{2}$ was calculated according to the performance of $\mathrm{PRO}_{1}$, as presented in Fig.9. The variation of $\mathrm{Q}_{\mathrm{FR}}$ is governed by the following relationship:

$\mathrm{Q}_{\mathrm{FR}}=\mathrm{Q}_{\mathrm{ad}}\left(1-\mathrm{DF}_{\mathrm{PRO}_{1}}\right)$

When the dilution factor of the first PRO stage increases, the $\mathrm{PRO}_{2}$ draw solution stream decreases and vice-versa. However, high dilutions lead to high osmotic pressures of $\mathrm{PRO}_{2}$ the draw solution due to the migration of the water from $Q_{a d}$ to $Q_{R}^{1}$. This increase of osmotic pressure is beneficial for energy generation, due to the fact that a high osmotic pressure difference enhances the PRO process. 


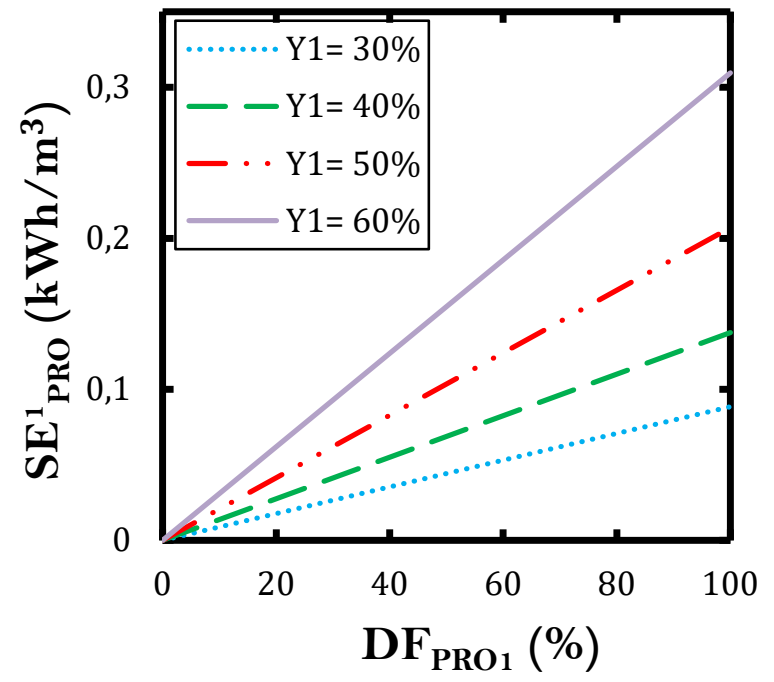

Fig.8: Specific energy production $S E_{P R O}^{1}$ of the first PRO sub-system ("2RO-2PRO” design) as a function of dilutions $\left(\mathrm{DF}_{\mathrm{PRO}_{1}}\right)$ for differentRO $\mathrm{O}_{1}$ recoveries.
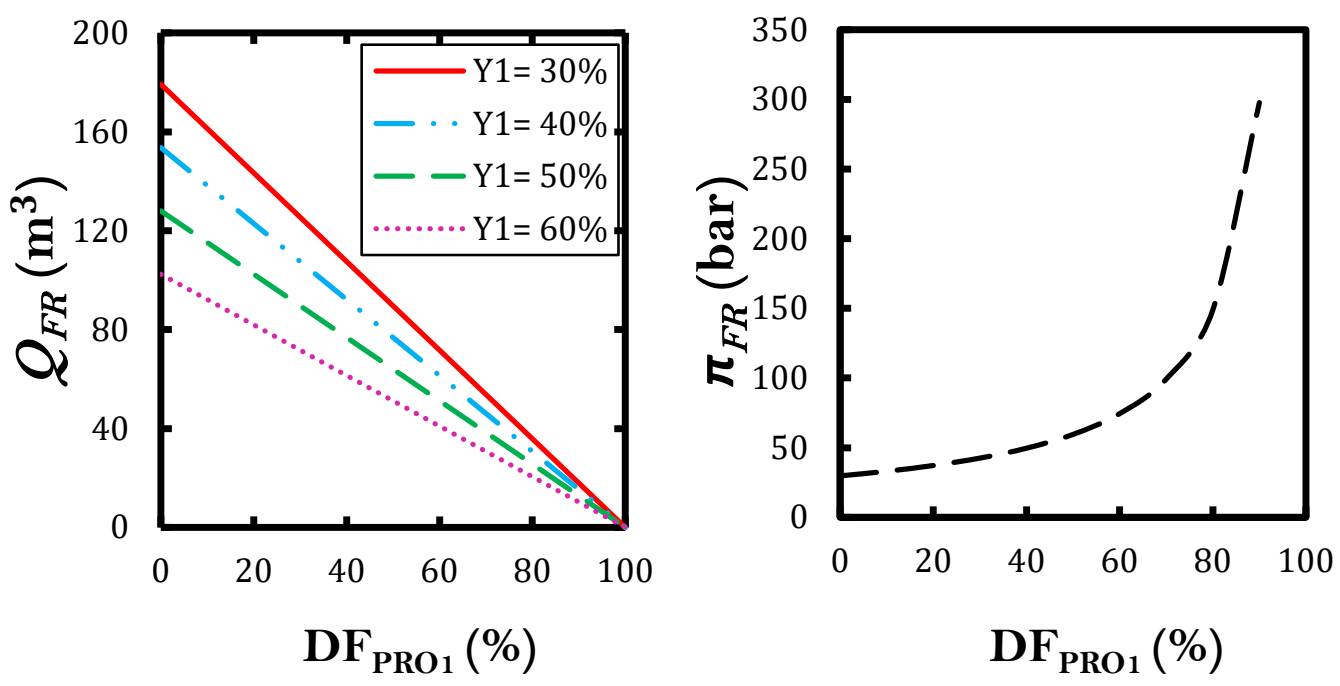

Fig.9: Amount of the feed bleed stream exiting the first PRO sub-system and its corresponding osmotic pressure as a function of dilutions $\left(\mathrm{DF}_{\mathrm{PRO}_{1}}\right)$.

Similar to the 2RO-1PRO model developed in section 2.3.2, the second PRO sub-system of the "2RO-2PRO” design is governed by Eq.(22). In fact, the feed and draw solution streams of $\mathrm{PRO}_{2}$ depend, respectively, on $\mathrm{Y}_{1}$ and $\mathrm{DF}_{\mathrm{PRO}_{1}}$. For this, the entering streams are not equal, so the dilution factor of the second PRO stage, $\mathrm{DF}_{\mathrm{PRO}_{1}}$, should be determined based on recoveries as well as the performance of the first PRO stage to calculate the energy produced. Following the same steps as section 2.3.3, the specific energy production of $\mathrm{PRO}_{2}, S E_{P R O}^{2}$, is:

$$
S E_{P R O}^{2.2}=\mathrm{DF}_{\mathrm{PRO}_{2}}(1-\phi)\left(C_{F R}-C_{R}^{2}\right) \frac{\beta R T}{2}
$$


where $\mathrm{DF}_{\mathrm{PRO}_{2}}$ is the dilution factor of the second PRO stage. $S E_{P R O}^{2.2}$ is presented in Fig.10. As can be clearly seen, the increase of the $\mathrm{RO}_{1}$ recovery induces a decrease in the energy produced. For example, the energy decreases by almost $50 \%$ when the recovery is increased from $40 \%$ to $60 \%$. This behavior is repeatable, regardless of the performance of the membrane, $x$. This result is attributed to the osmotic pressure increase of $\mathrm{Q}_{\mathrm{R}}^{1}$ and the decrease of $Q_{F R}$ flow. The energy recovered by the system is the sum of energies produced by both $\mathrm{PRO}_{1}$ and $\mathrm{PRO}_{2}$. The total Specific energy production $S E_{P R O_{1}+P R O_{2}}$ is presented in Fig.11. It can be clearly seen that the energy produced decreases in line with the increase of the $\mathrm{RO}_{1}$ recovery. For low dilutions, the total energy produced is not significant when operating at low recoveries. In this situation, the energy produced becomes significant only for high dilutions $\left(\mathrm{DF}_{\mathrm{PRO}_{2}} \geq 60 \%\right)$. For example, the energy produced at $40 \%$ dilution $(x=0.8)$ is only $0.13 \mathrm{kWh} / \mathrm{m}^{3}$ when $\mathrm{Y}_{1}=30 \%$, whereas it is $0.7 \mathrm{kWh} / \mathrm{m}^{3}$ at $80 \%$ dilution, which corresponds to more than a five times increase for only a doubled dilution.

For relatively high recoveries, total SEPRO is still significant when the dilution is relatively low. In sum, at low recoveries and relatively high dilution, the contribution of the second PRO stage in energy recovery is more important in comparison to the second PRO stage. However, at high recovery rates, the first PRO stage contributes more in energy recovery. As a comparison between the two designs, Fig.7 and Fig.11 show that the performance of "2RO-2PRO” is much better than "2RO-1PRO”. As most desalination plants operate under $40 \%-50 \%$ recovery rates, the energy that can be produced using " $2 \mathrm{RO}-1 \mathrm{PRO}$ " ranges between 0.11 to $0.19 \mathrm{kWh} / \mathrm{m}^{3}$. For “2RO-2PRO”, the energy ranges between 0.7 to $0.93 \mathrm{kWh} / \mathrm{m}^{3}$. Of course the addition of a second PRO stage will increase the capital cost of the SWRO-PRO process, but an economic study should be carried out to confirm or deny the feasibility of this design. Compared to the theoretical values of extractable energy (e.g. Gibbs energy of mixing), the realistic results are far from the theoretical calculated energy. In fact, this expected result is caused by the low mixing rate due to membrane performance and energy losses (frictional losses and unused energy). 

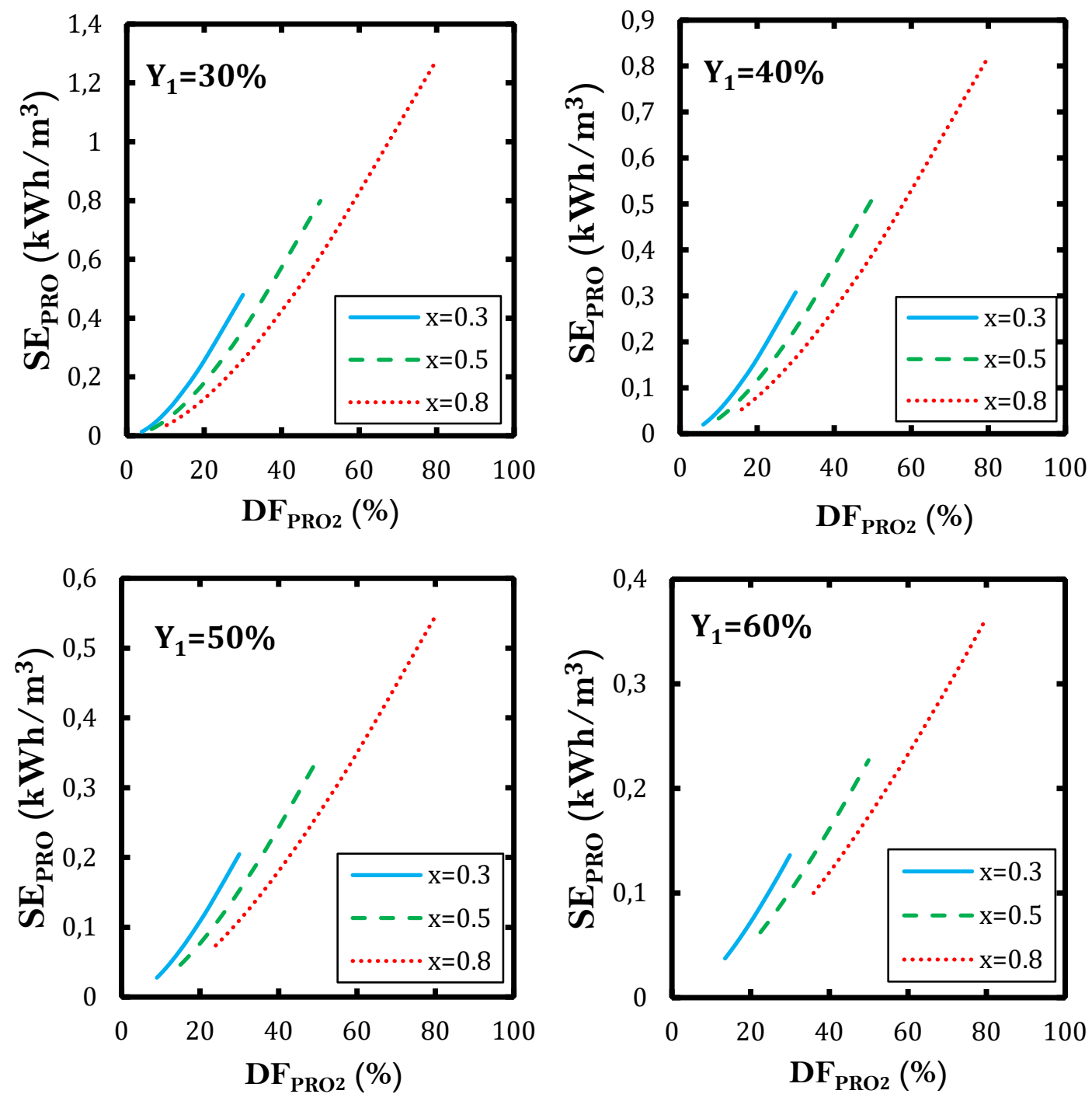

Fig.10: Specific energy production $S E_{P R O}^{2}$ of the second PRO sub-system ("2RO-2PRO" design) as a function of dilutions $\left(\mathrm{DF}_{\mathrm{PRO}_{2}}\right)$ for different $\mathrm{RO}_{1}$ recoveries. 

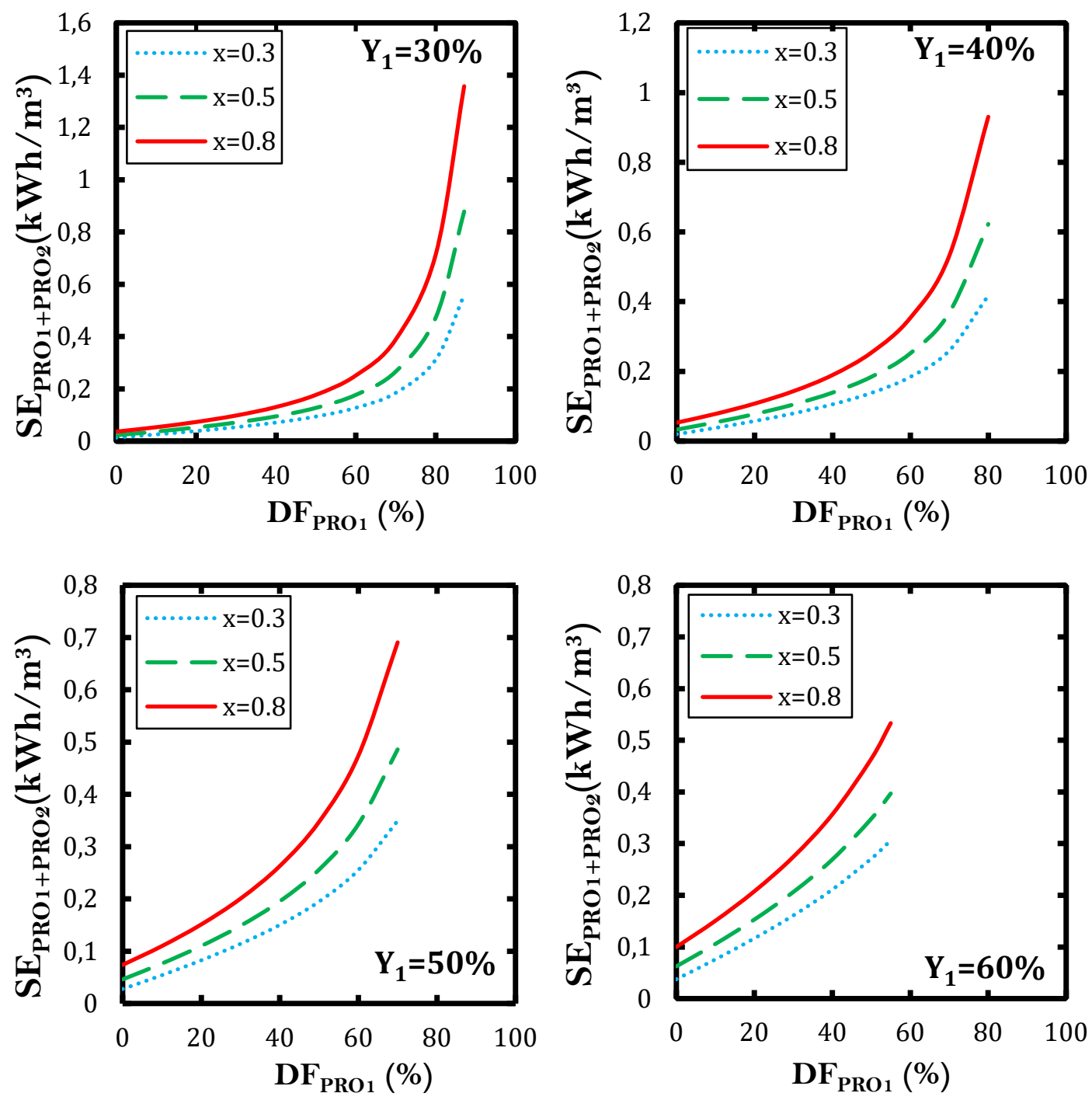

Fig.11: Total Specific energy production $S E_{P R O_{1}+P R O_{2}}$ of the "2RO-2PRO" design as a function of dilutions $\left(\mathrm{DF}_{\mathrm{PRO}_{1}}\right)$ for different $\mathrm{RO}_{1}$ recoveries.

\subsection{Maximum of dilution model validation}

During the previous section, the dilution factor was modeled based on the membrane performance and the feed flow ratio to estimate the energy produced by PRO, especially when the PRO entering flows are not equal. To verify the DF model, $\Delta \mathrm{Q}$ is determined using pressure and flow balances for the "2RO-1PRO" design. The same methodology can be used for the second configuration "2RO-2PRO". The power recovered in PRO is maximized the osmotic pressure difference between the feed and draw solutions is equal to the hydraulic pressure difference $\Delta P$. The draw solution exits the module under an osmotic pressure equal to the sum of the osmotic pressure of the feed flow, $\mathrm{Q}_{\mathrm{R}}^{2}$, and the applied hydraulic pressure $\Delta P$. This equilibrium can be described as follows: 
$\pi_{\mathrm{R}}^{2}+\Delta \mathrm{P}=\frac{\mathrm{Q}_{\mathrm{sw}} \pi_{\mathrm{sw}}}{\left(1-\mathrm{Y}_{1}\right) \mathrm{Q}_{\mathrm{sw}}+\Delta \mathrm{Q}}$

where $\pi_{R}^{2}$ is the osmotic pressure of the second stage rejected water. Similarly, the feed flow exits the module under an osmotic pressure equal to the osmotic pressure of $\mathrm{Q}_{\mathrm{R}}^{1}$, subtracted from the applied hydraulic pressure $\Delta P$. The equilibrium condition at the draw inlet side of the PRO module is expressed as:

$\pi_{\mathrm{sw}}=\frac{\mathrm{Q}_{\mathrm{R}}^{2} \pi_{\mathrm{R}}^{2}}{\mathrm{Q}_{\mathrm{R}}^{2}-\Delta \mathrm{Q}}+\Delta \mathrm{P}$

As mentioned previously, the optimum applied pressure is the half of the osmotic pressure difference. Hence, , $\Delta P$ is expressed in this case as:

$\Delta \mathrm{P}=\frac{\pi_{\mathrm{sw}}}{2\left(1-\mathrm{Y}_{1}\right)}$

To calculate $\Delta \mathrm{Q}$, Eqs. (26) and (27) are solved simultaneously using the condition presented in Eq. (28). Solving the equation system yields:

$\Delta \mathrm{Q}=\mathrm{Q}_{\mathrm{R}}^{2}\left(1-\frac{\pi_{\mathrm{R}}^{2}}{\pi_{\mathrm{sw}}} \frac{2-2 \mathrm{Y}_{1}}{1-2 \mathrm{Y}_{1}}\right)$

Finally, the expression of the dilution factor is:

$\mathrm{DF}=\frac{\Delta \mathrm{Q}}{\mathrm{Q}_{\mathrm{R}}^{1}}=\mathrm{Y}_{1} \frac{1-\mathrm{Y}_{2}}{1-\mathrm{Y}_{1}}\left(1-\frac{\pi_{\mathrm{R}}^{2}}{\pi_{\mathrm{sw}}} \frac{2-2 \mathrm{Y}_{1}}{1-2 \mathrm{Y}_{1}}\right)$

For the critical recovery $\mathrm{Y}_{1}=50 \%$, the dilution factor is calculated using:

$\lim _{Y_{1} \rightarrow 0.5} D F=0.3$

Fig.12 shows the results of maximum dilution obtained using Eq.(30) for different recoveries using the "2RO-1PRO” design. This result is compared to Fig.6 (right, $x=1$ ). It can be seen clearly that the results are similar for the range of recovery studied. The 
[Escriba aquí]

same methodology is used to calculate the maximum dilution for the second design by modifying Eqs. (26), (27), (28) and (29) using the corresponding streams and osmotic pressures.

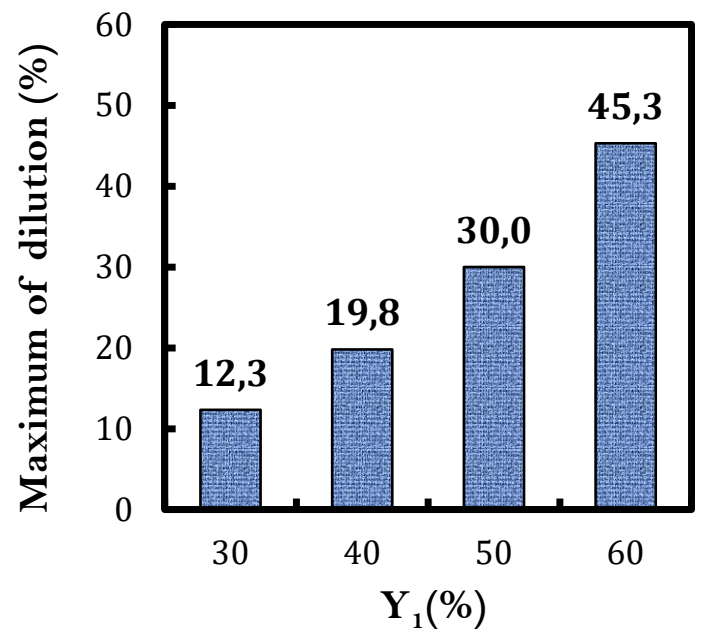

Fig.12: Maximum dilution for different $\mathrm{RO}_{1}$ recoveries.

\section{Effect of the SWRO initial feed concentration $C_{s w}$ and stream $Q_{s w}$}

The impact of feed salinity upon the performance of the PRO process was evaluated using three feed salinities; 35, 40 and $45 \mathrm{~g} / \mathrm{L}(0.6,0.68$ and 0.77M) for both proposed designs. This range of concentration simulates the distribution of the seawater salinity worldwide. The dilution factor was chosen arbitrarily to be $60 \%$. Fig. 13 shows the variation of the specific energy production of the SWRO-PRO process. It is obvious that the increase of the RO feed concentration leads to the increase of the energy produced regardless of the design used. In fact, the RO feed concentration increase increases the concentration of the RO brine, which is the draw solution of the PRO sub-systems; then the osmotic pressure difference increases and enhances the water passage across the membrane. For (A), which presents the results of the first design, the increase of the concentration from 35 to $45 \mathrm{~g} / \mathrm{L}$ induces an increase of the recovered energy of only $0.02 \mathrm{kWh} / \mathrm{m}^{3}$ at $50 \%$ recovery. For (B), the second design case, the energy recovered is $0.1 \mathrm{kWh} / \mathrm{m}^{3}$ at $50 \%$ recovery. However, under the same conditions, the energy consumption SEC Swro increases by $0.86 \mathrm{kWh} / \mathrm{m}^{3}$. This fact shows that the energy consumption increase rate is much more rapid than the energy recovered increase rate when the feed salinity increases. The effect of the inlet RO feed stream is also discussed. The amount of the initial $\mathrm{Q}_{\text {sw }}$ was varied from $256 \mathrm{~m}^{3} / \mathrm{h}$ to $50000 \mathrm{~m}^{3} / \mathrm{h}$ and the dilution factor was chosen arbitrarily to be $60 \%$ for both PRO stages. The increase of the RO capacity enhances the energy recovery 
for both studied designs. This fact is due to the increase of water flux across the PRO membrane which increases the output energy.

It can also be seen that the energy increase tends to reach a maximum where the increase of the $\mathrm{Q}_{\mathrm{sw}}$ has no effect (Fig 13-C and D). The latter result is attributed to the fact that the increases of $\mathrm{Q}_{\mathrm{sw}}$ leads to the decrease of $\phi$ at low values ( $\phi<<0.5$ ), which limits the performance of the PRO. Increasing the initial feed flow will certainly increase the capital cost of the SWRO-PRO process because of the need for a greater PRO membrane surface, suitable pressure exchangers and turbines. Further work must be done in this direction.
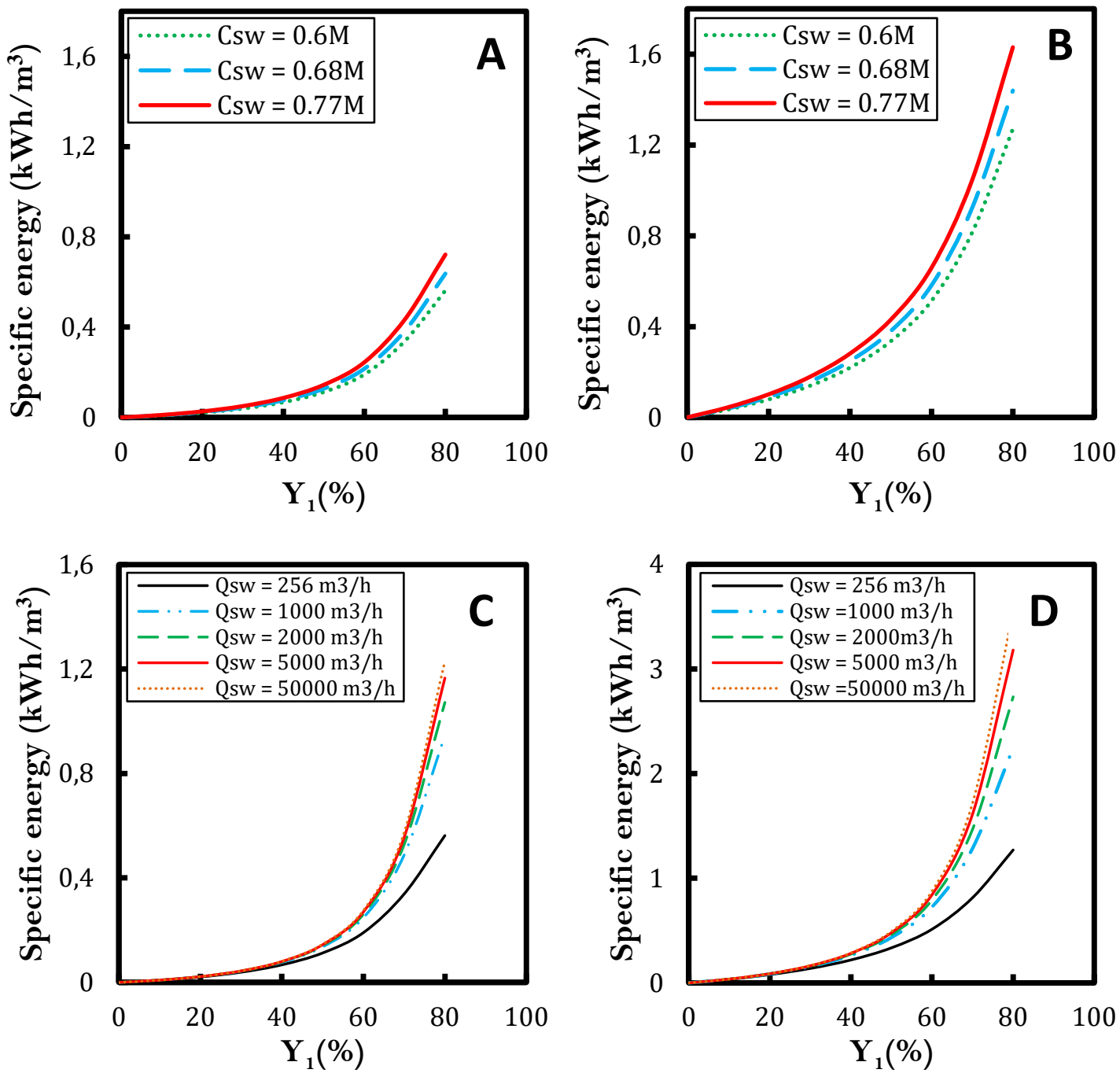

Fig.13: Specific Energy production of SWRO-PRO for different RO feed concentrations and flows. (A) and (C) for one-stage PRO. (B) and (D) for two-stage PRO.

\section{Effect of the second stage recovery}


Throughout the previous sections, the recovery rate of the second SWRO, $\mathrm{Y}_{2}$, was arbitrarily fixed according to the suggestions of the constructor and the production needs. In this section, the variation of the second stage recovery is studied. For this, three possible values of $\mathrm{Y}_{2}$ were investigated (e.g., $60 \%, 70 \%$ and $80 \%$ ). The increase of $\mathrm{Y}_{2}$ leads to more energy consumption according to Eq.( 9). The variation of the energy consumption with $\mathrm{Y}_{2}$ is shown in Fig.14-b. Increasing the recovery from $70 \%$ to $80 \%$ causes a rise in SECswro by $0.7 \mathrm{kWh} / \mathrm{m}^{3}$. On the other hand, decreasing the recovery to $60 \%$ reduces the energy consumption by $0.35 \mathrm{kWh} / \mathrm{m}^{3}$. The energy recovered by the total system (using the second design here) is presented in Fig.14-a. It can be seen that the increase of $\mathrm{Y}_{2}$ reduces the energy recovery. This is due to the increase in the PRO feed stream at low $\mathrm{Y}_{2}$, which increases the initial feed flow ratio to approach 0.5 , and increases the dilution factor, so the energy increases. Overall, lower second stage recovery reduces the energy consumption and increases the energy recovery. In this case, the choice of the second stage recovery is primordial, due to the fact that the industrial process of the present unit depends on it. Consequently, it is advisable for the operators to reduce the recovery of the second stage when the production rate of the electrolyzation process is decreased to reduce the SEC and to increase the energy recovery.
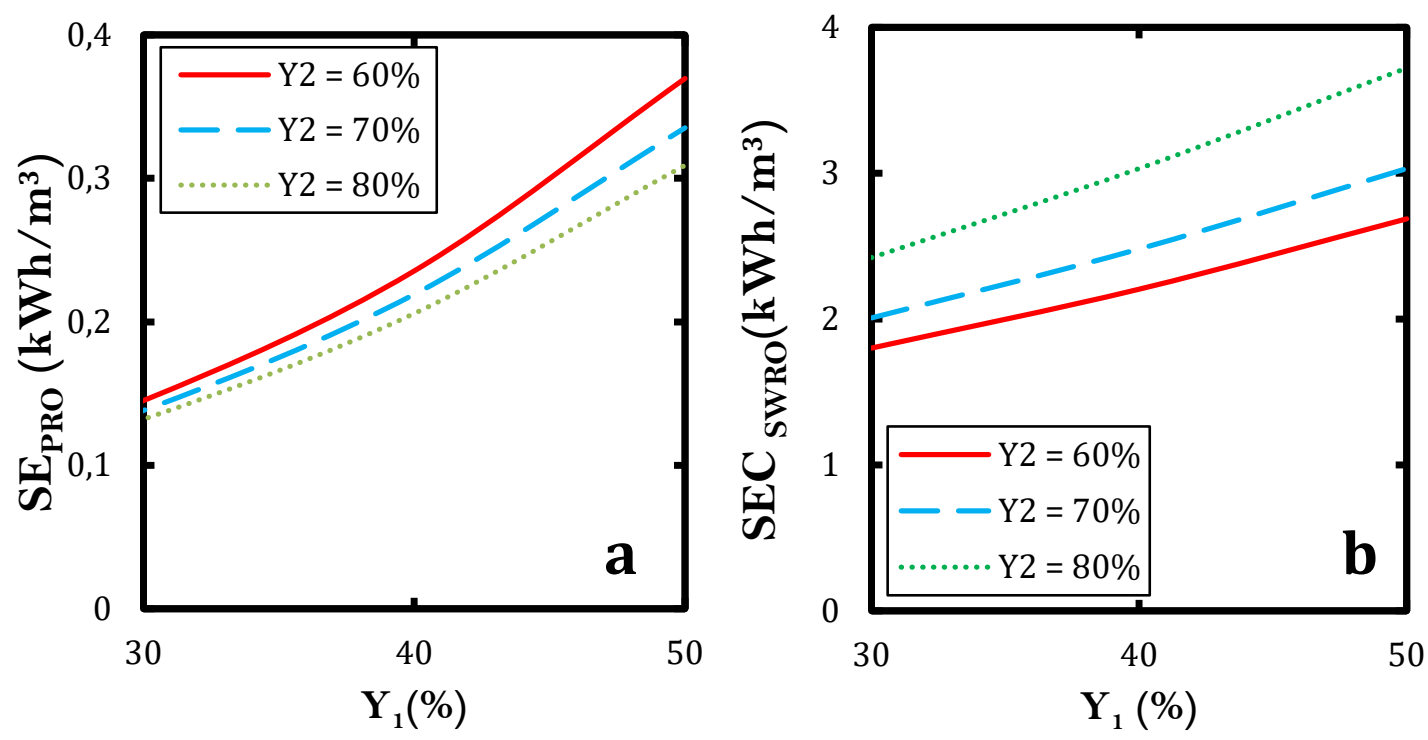

Fig.13: Specific Energy production of SWRO-PRO and specific energy consumption of SWRO for different RO second stage recovery. The calculation of the energy recovered (a) was carried out using results developed previously for the second SWRO-PRO design.

\section{Conclusions}


[Escriba aquí]

In the current study, two configurations for the integration of Pressure Retarded Osmosis were studied, that provide additional energy recovery for existing Seawater Reverse Osmosis plants without the requirement of additional feed sources. To analyze the effect, a mathematical model describing the energy produced was first developed for both configurations. The first SWRO-PRO design (“1RO-2PRO” design) shows a low performance at the recommended recovery ratio for the RO process (40-50\%), as compared to the second design ("2RO-2PRO” design). We expect more recovered energy for the first configuration if the feed solution is provided from outside the system, due to the fact that the present feed solution is coming from the brine of the second stage, which provides low water flows. The study showed that the capacity of the SWRO and the initial seawater concentration strongly affect the performance of PRO. The additional elements to the SWRO unit require an increase in the capital cost of the process, so as further work an economic study should be done to reveal when the incorporation of two PRO subsystems, is economically feasible.

\section{ACKNOWLEDGEMENTS}

This work was supported by MiCInn 2014-54530-R. J. Salamanca thanks the financial support given by MiCInn. We also acknowledge the personnel of SETA S.L. for many helpful contributions.

\section{Symbols}


[Escriba aquí]

$A_{m} \quad$ Membrane surface. $\left(\mathrm{m}^{2}\right)$

$C_{D}^{0} \quad$ Initial molar concentration of the draw solution. (mole/l)

$C_{F}^{0} \quad$ Initial molar concentration of the feed solution. (mole/l)

$\mathrm{C}_{\mathrm{F}} \quad$ Molar concentration of the feed solution. (mole/l)

$\mathrm{C}_{\mathrm{D}} \quad$ Molar concentration of the draw solution. (mole/l)

$\mathrm{C}_{\mathrm{M}} \quad$ Molar concentration of the mixed solution. (mole/l)

$C_{\text {FIN }}$ Final concentration of the mixed solution at $\Delta \pi=0$. (mole/l)

$\mathrm{n}_{\mathrm{M}} \quad$ Total amounts (in moles) of mobile species in the mixed solution. (mole)

$\mathrm{n}_{\mathrm{F}} \quad$ Total amounts (in moles) of mobile species in thefeed. (mole)

$\mathrm{n}_{\mathrm{D}} \quad$ Total amounts (in moles) of mobile species in draw solutions. (mole)

Q $\quad$ The added flow of seawater as a feed solution for the second design. $\left(\mathrm{m}^{3} / \mathrm{h}\right)$

$Q_{D}^{0} \quad$ Initial draw solution stream. $\left(\mathrm{m}^{3} / \mathrm{h}\right)$

$Q_{F}^{0} \quad$ Initial feed solution stream. $\left(\mathrm{m}^{3} / \mathrm{h}\right)$

QFR The feed solution bleed stream of the first PRO sub-system. $\left(\mathrm{m}^{3} / \mathrm{h}\right)$

$\mathrm{Q}_{\mathrm{sw}} \quad$ Seawater flow rate. $\left(\mathrm{m}^{3} / \mathrm{h}\right)$

QR1 Flow rate of the first stage brine. $\left(\mathrm{m}^{3} / \mathrm{h}\right)$

QR2 Flow rate of the second stage brine. $\left(\mathrm{m}^{3} / \mathrm{h}\right)$

$\Delta Q \quad$ The amount of flow that crosses from feed to draw side. $\left(\mathrm{m}^{3} / \mathrm{h}\right)$

$\Delta Q_{F I N}$ The final amount of flow that crosses from feed to draw sideat $\Delta \pi=0 .\left(\mathrm{m}^{3} / \mathrm{h}\right)$

$\mathrm{R} \quad$ The ideal gas constant. $(\mathrm{J} / \mathrm{mol} / \mathrm{K})$

$r \quad$ Ratio between the feed and draw flows. (-)

$\mathrm{T} \quad$ The absolute temperature. $\left({ }^{\circ} \mathrm{K}\right)$

$W_{Q_{F}^{0}}^{\text {ideal }}$ Specific Ideal work. $(\mathrm{kJ})$

$x_{\mathrm{i}, \mathrm{M}} \quad$ The mole fraction of species "i” in the mixed solution. (-)

$x_{\mathrm{i}, \mathrm{F}} \quad$ The mole fraction of species " $\mathrm{i}$ " in the feed solution. (-)

$x_{\mathrm{i}, \mathrm{D}}$ The mole fraction of species "i”" in the draw solution. (-)

$\mathrm{Y}_{1} \quad$ First stage RO recovery. (-) 
[Escriba aquí]

$\mathrm{Y}_{2}$ Second stage $\mathrm{RO}$ recovery. (-)

$\gamma_{i, M} \quad$ The activity coefficients of species "i”"in the mixed solution. (-)

$\gamma_{\mathrm{i}, \mathrm{F}} \quad$ The activity coefficients of species " $\mathrm{i}$ " in the feed solution. (-)

$\gamma_{\mathrm{i}, \mathrm{D}} \quad$ The activity coefficients of species "i" in the draw solution. (-)

$\beta \quad$ The van't Hoff factor. (-)

$\phi \quad$ Feed flow rate fraction. (-)

$\pi_{\text {feed }}$ Osmotic pressure of feed solution. (bar)

$\pi_{s w} \quad$ Osmotic pressure of seawater. (bar)

$\pi_{\mathrm{FR}} \quad$ Osmotic pressure of the feed solution bleed of the first PRO sub-system. (bar)

$\pi_{\mathrm{R} 1} \quad$ Osmotic pressure of the first stage brine. (bar)

$\pi_{\mathrm{R} 2} \quad$ Osmotic pressure of the second stage brine. (bar)

$\Delta \mathrm{G}_{\mathrm{nM}}$ The energy per mole of mixed solution in an isothermal and isobaric process. $(\mathrm{kJ})$

$\Delta P \quad$ Theapplied pressure. (bar)

$\Delta \pi \quad$ The difference of osmotic pressure between the fed and draw solutions.(bar)

\section{REFERENCES}


[Escriba aquí]

[1] Ghaffour N, Missimer TM, Amy GL. Technical review and evaluation of the economics of water desalination: current and future challenges for better water supply sustainability. Desalination 2013;309:197-207

[2] Hun Jung Y, Hoon Jeong Y, Choi J, F. Wibisono A, Lee JI, Cheon No H. Feasibility study of a small-sized nuclear heat-only plant dedicated to desalination in the UAE. Desalination 2014:337;83-97.

[3] Fragkou MC, McEvoy J. Trust matters: Why augmenting water supplies via desalination may not overcome perceptual water scarcity. Desalination 2016;397: 18.

[4]Pedro-Monzonís M, Solera A, Ferrer J, Estrela T, Paredes-Arquiola J. A review of water scarcity and drought indexes in water resources planning and management. Journal of Hydrology 2015;527: 482-493.

[5] Goh PS, Matsuura T, Ismail AF, Hilal N. Recent trends in membranes and membrane processes for desalination. Desalination 2016; 391:43-60.

[6]Burn S, Hoang M, Zarzo D, Olewniak F, Campos E, Boltoa B, Barron O. Desalination techniques - A review of the opportunities for desalination in agriculture. Desalination 2015;364:2-16.

[7]Wenten IG, Khoiruddin. Reverse osmosis applications: Prospect and challenges, Desalination (2015), http://dx.doi.org/10.1016/j.desal.2015.12.011

[8]Jeffrey MG, Hui TC. Thermodynamic perspective for the specific energy consumption of seawater desalination. Desalination 2016;386:13-18.

[9]Safarpour M, Khataee A, Vatanpour V. Thin film nanocomposite reverse osmosis membrane modified by reduced graphene oxide/TiO2 with improved desalination performance. J Membr Sci 2015;489: 43-54.

[10]Yan W, Wang Z, Wu J, Zhao S, Wang J, Wang S. Enhancing the flux of brackish water TFC RO membrane by improving support surface porosity via a secondary pore-forming method. J Membr Sci 2016;498:227-241.

[11] S. Richards B, P.S. Capão D, G. Früh W, I. Schäfer A. Renewable energy powered membrane technology: Impact of solar irradiance fluctuations on performance of a brackish water reverse osmosis system. Sep Purif Technol 2015;156(2):379-390

[12]Alvarez-Silva O, Winter C, F. Osorio A. Salinity Gradient Energy at River Mouths. Environ Sci Technol Lett 2014;1:410-415.

[13]Eltawil MA, Zhengming Z, Yuan L. A review of renewable energy technologies integrated with desalination systems. Renew Sust Energ Rev2009;13: 2245-2262. 
[Escriba aquí]

[14]Helfer F, Lemckert C. The power of salinity gradients: An Australian example. Renew Sust Energ Rev 2015;50:1-16.

[15] Alvarez-Silva O, F. Osorio A, Winter C. Practical global salinity gradient energy potential. Renew Sustain Energ Rev 2016;60:1387-1395.

[16]Touati K, Tadeo F. Green energy generation by Pressure Retarded Osmosis: State of the art and technical advancement -review. International Journal of Green Energy (accepted manuscript).

[17] Chung T-S, Luo L, Wan C F, Cui Y, Amy G. What is next for forward osmosis (FO) and pressure retarded osmosis (PRO) Sep Purif Technol 2015; 156:856-860. .

[18] Raventos N, Macpherson E, García-Rubiés A. Effect of brine discharge from a desalination plant on macro-benthic communities in the NW Mediterranean. Mar Environ Res 2006;62:1-14

[19] Wan CF, Chung T-S. Maximize the operating profit of a SWRO-PRO integrated process for optimal water production and energy recovery. Renew Energy 2016;94:304-313.

[20] Kim J, Park M, A. Snyder S, Kim JH. Reverse osmosis (RO) and pressure retarded osmosis (PRO) hybrid processes: Model-based scenario study. Desalination 2013; 322: $121-130$.

[21] He W, Wang Y, Sharif A, Hasan Shaheed M. Thermodynamic analysis of a standalone reverse osmosis desalination system powered by pressure retarded osmosis. Desalination 2014;352:27-37.

[22] Achilli A, Prante JL, Hancock NT, Maxwell EB, Childress AE, Experimental results from RO-PRO: A next generation system for low-energy desalination. Environ Sci Technol 2014;48 (11):6437-43.

[23]Palacin LG, Tadeo F, De Prada C, Touati K. Evaluation of the recovery of osmotic energy in desalination plants by using pressure retarded osmosis. Desalin and Wat Treat 2013;51(1-3):360-365.

[24] Prante JL, Ruskowitz JA, AE Childress, Achilli A, RO-PRO, desalination: An integrated low-energy approach to seawater desalination. Appl Energy 2014;120:104-14.

[25] Wan CF, Chung T-S. Osmotic power generation by pressure retarded osmosis using seawater brine as the draw solution and wastewater retentate as the feed. J Memb Sci 2015;479:148-158. 
[Escriba aquí]

[26]Lin S, Elimelech M. Staged reverse osmosis operation: Configurations, energy efficiency, and application potential. Desalination 2015;366:9-14.

[27]www.h2ocean-project.eu.

[28] Touati K, Hänel C, Tadeo F, Schiestel T. Effect of the feed and draw solution temperatures on PRO performance: theoretical and experimental study. Desalination 2015;365:182-195.

[29] Touati K, de la Calle A, Tadeo F, Roca L, Schiestel T, Alarcón-Padilla DC. Energy recovery using salinity differences in a multi-effect distillation system. Desalin Water Treat 2014:1-8.

[30] Yip NY, Elimelech M. Thermodynamic and energy efficiency analysis of power generation from natural salinity gradients by pressure retarded osmosis. Environ Sci Technol 2012;46:5230-5239.

[31] Smith JM, Ness H Van, Abbott MM. Introduction to Chemical Engineering Thermodynamics, McGraw-Hill Professional, 2005.

[32] Touati K, Tadeo F, Hänel C, Schiestel T. Effect of the operating temperature on hydrodynamics and membrane parameters in pressure retarded osmosis. Desalin Water Treat. (2015) 1-13, http://dx.doi.org/10.1080/19443994.2015.1039600

[33] Avlonitis SA, Kouroumbas K, Vlachakis N. Energy consumption and membrane replacement cost for seawater RO desalination plants. Desalination 2003;157:1518.

[34]P. Straub A, Lin S, Elimelech M. Module-scale analysis of Pressure Retarded Osmosis: performance limitations and implications for full-scale operation. Environ Sci Technol 2014;48:12435-12444.

[35]P. Straub A, L, Elimelech M. Pressure-retarded osmosis for power generation from salinity gradients: is it viable?. Energy Environ Sci 2016;9:31-48

[36] Touati K, Tadeo F. Study of the Reverse Salt Diffusion in pressure retarded osmosis: Influence on concentration polarization and effect of the operating conditions. Desalination 2016;389:171-186.

[37] Attarde D, Jain M, Gupta SK. Modeling of a forward osmosis and a pressureretarded osmosis spiral wound module using the Spiegler-Kedem model and experimental validation. Sep Purif Technol 2016;164:182-197.

[38]Kim J, Jun Park M, Park M, Shon HK, Kim S-H, Kim JH. Influence of colloidal fouling on pressure retarded osmosis. Desalination 2016;389: 207-214. 
[Escriba aquí] 